\title{
Evolutionary Changes in Service Attribute Importance in a Crisis Scenario
}

\section{The Uruguayan Financial Crisis}

\author{
Moshe Kim \\ University of Haifa, Israel and Universitat Pompeu Fabra \\ Nora Lado \\ Carlos III University
}

Anna Torres

Universitat Pompeu Fabra

\begin{abstract}
This article attempts to identify and assess the evolution of consumers' differential reactions to major service attribute classes that resulted from and were propagated by a severe financial crisis. The authors perform a longitudinal analysis, using correspondence analysis of square asymmetric matrices, on data generated from three different postcrisis time periods. The first period encompasses data during the 2 weeks after the crisis occurred, the second period assesses data 1 year later, and the third period refers to 5 years later. The results from the first and second periods both indicate the growing importance of credence attributes rather than search attributes compared with during the precrisis period. The third-period analysis indicates a reversal and greater importance of the search attributes that were important in the precrisis period. The results also reveal correlations with the type of banking organization. These findings point to important managerial implications; bank management's inability to realize the shift in consumers' attitudes failed to facilitate and expedite a resolution to the crisis.
\end{abstract}

Keywords: financial marketing; crisis; service attribute importance; correspondence analysis

\section{Introduction}

Service firms increasingly suffer greater exposure and vulnerability to crises, due to both the nature of the service itself and the intensity of interactions and interdependency among the elements of service industries. In the modern competitive arena, firms are not independent entities but rather interconnected parts of networks. Industries such as transportation or tourism now feature networks competing against networks. The impact of a crisis (e.g., caused by terrorism or natural disasters) in one element of the network will affect the

\footnotetext{
Authors' Note: The authors are grateful to the editor Prof. Parasuraman and three anonymous referees for their comments and suggestions which greatly improved the paper's contents and exposition. The authors wish to thank Xavier Freixas, Michael Greenacre and Oscar Licandro for their helpful comments on previous versions of this paper. Financial support of the Spanish Ministry of Education and Science (projects SEJ2006-14098, and SEJ2007-65897) is gratefully acknowledged.
}

other elements. In such a crisis situation, customers have trouble retaining their confidence in the service, yet confidence plays a key role in the development of long-term relationships between clients and service providers (Hennig-Thurau, Gwinner, and Gremler 2002; Smith 2005). The breach of confidence associated with an uncertain, stressful crisis situation therefore represents an important and complex managerial challenge.

To understand the potential effects of severe crises on customers' behavior and attitudinal changes toward various service attributes, this research evaluates evolutionary changes in the perceived importance of service attributes caused by a severe, exogenous, and stressful shock. The specific event under investigation is the collapse of the financial system in Uruguay in June 2002. We analyze consumer reactions, characterized by high levels of uncertainty avoidance (Hofstede 1991), in particular. Previous research into service attribute importance tends to investigate stable scenarios or static 
analyses, or it fails to differentiate among the different types of financial institutions (Paswan et al. 2004). Thus, Zurawicki and Braidot (2005) mention that customer reactions during a crisis remain important but scantily researched issues. This study explores the (dynamic) evolution of consumer attitude changes in response to a nonstable (crisis) scenario, including search, experience, and credence attributes, and investigates the possible dependence of consumers' reactions to crisis on the type of banking organizations.

Following existing literature, we consider trust, security, and honesty credence attributes (Blois 1999), whereas we classify yield as a search attribute and good service, competent personnel, and customer care as experience attributes (Nelson 1970, 1974; Srinivasan and Till 2002). The differential importance consumers confer on search, credence, or experience attributes will likely be affected severely by exogenous, unanticipated, and powerful shocks (Miller and Ginter 1979). Thus, a study of the evolution of consumer's' differential reactions regarding these major attribute classes, especially after severe crises, can be quite fruitful. This investigation should prove particularly useful in terms of managerial implications; in the case we present herein for example, bank management continued to tout yields in its advertising, but consumers were no longer interested in search attributes such as yields and instead sought credence attributes such as trust and security.

Why should we be interested in the evolution of consumers' attitudes resulting from a financial crisis in general and that emanating from the Uruguayan crisis in particular? First, the financial sector represents a specific business environment, uniquely characterized by intertemporal and therefore uncertain outcomes. The purchase and sale of banking products requires special, nonanonymous, dynamic relationships between buyers and sellers over an extended period of time; thus, it is plagued by problems associated with asymmetric information between the transacting parties (Boot 2000). In turn, credence attributes play a major role in this business environment (Blois 1999), though the need for a close relationship cannot diminish the importance of the basic (core) product characteristic, namely, financial yields. A severe exogenous shock in this environment should result in significant effects on the nature of the previously established relationships and their characteristics (Miller and Ginter 1979).

Second, during the past quarter century, many banking crises have occurred around the world (Samartín 2002). Caprio and Klingebiel (1996) document 69 crises in developed and emerging market countries since the late 1970s. Moreover, the costs to the economy are enormous; Hoggarth, Reis, and Saporta (2002) demonstrate that the cumulative output losses incurred during crisis periods are huge, roughly $15 \%$ to $20 \%$, on average, of annual gross domestic product.

Third, the Uruguayan crisis provides an instructive case. Over a long period prior to the crisis, Unuguayan banks had benefited from their sound reputation and enjoyed an adequate level of confidence. Yet the massive contraction in the economy, together with economic overdependence on neighboring Argentina, caused the Uruguayan crisis of June 2002. The Uruguayan government shut down four domestic banks, froze deposits, and declared a 4-day "banking holiday" (cessation of all banking activities) to prevent depositors from withdrawing excessive funds from banks in what is popularly termed a run on the bank. At the end of 2003, the Uruguay's economy had stabilized, with an exceptionally high annual growth rate of $10 \%$, and the Uruguayan case has been recognized as an excellent example of effective policies that a country should have in place when exposed to a financial crisis.

Because financial markets provide similar, "standardized" basic services, regardless of their geographical or cultural origin, the collapse and evolutionary reaction to the Uruguayan crisis may be instructive for public policy makers in general and managers of financial institutions in particular in other countries. The phenomenon of financial contagion has epidemiological characteristics (Boschi 2005), and severe financial crises represent among the most traumatic experiences suffered by countries, because they involve severe reductions in purchasing power and command over real resources. Their effects therefore might not be directed solely toward a particular product of a particular geographical location. Studying the effects of severe financial crises can build a body of knowledge with which to validate important empirical regularities. Understanding these regularities in turn can facilitate policy and management reactions to help ameliorate crisis-related problems.

We should emphasize that in general, international (foreign) customers who use Uruguayan banking services originate in neighboring Mercosur countries, which exhibit high uncertainty avoidance index scores, similar to that of Uruguay, and therefore represent cohorts with similar risk aversion attitudes (Hofstede 1991). Moreover, all our respondents are Uruguayan and thus likely possess similar uncertainty avoidance characteristics. However, unlike a recent study (Zurawicki and Braidot 2005) assessing the reactions of consumers in neighboring Argentina to its financial crisis during a 
static time period (2001-2002), which documents inertia in commodity-specific prices, we address the intertemporal dynamic evolution of reactions, as well as differential behavior toward unique attribute types.

Fourth, we note the critical importance of highlighting the evolutionary changes in consumers' attitudes toward product attributes in the presence of a severe exogenous shock and the different reactions to this shock by clients of different types of institutions. The faster management can functionally recognize shifts in customers' attitudes, the faster it can influence purchasing behavior. For policy makers, understanding such shifts can facilitate their ability to align customers' behavior with the objective reality (end of the crisis) and thus positively affect real economic activity (Pennings, Wansink, and Meulenberg 2002). As our research reveals, management's apparent inability to affect customers' perceptions about the (objective) end of the crisis resulted in a significant gap between the objective end and customers' subjective evaluation of that ending.

Fifth, we investigate whether attitudinal changes are short-lived and transitory, amounting essentially to short-run overshooting, or whether such perceptions are deterministic and continue over a much longer time period. To do so, we repeat our analysis in subsequent years.

\section{Literature Review}

The service literature emphasizes the relevance of attribute weighting for measuring the determinant attributes of service quality evaluations (Carvalho and Leite 1999; Teas and De Carlo 2004). In a seminal work, Miller and Ginter (1979) find empirical support for the hypothesis that the importance of different attributes varies according to the situation. They adopt the definition of a situation suggested by Belk (1974), namely, "all those factors particular to a time and place, of observations which do not follow from knowledge of personal (intra-individual) and stimulus (choice alternative) attributes, and which have a demonstrable and systematic effect on current behavior" (p. 157). This definition distinguishes among the impact of the individual, the situation (pre- and postcrisis), and the object of the stimulus (the brand) on consumer behavior.

Service quality evaluation results from a comparison between the consumer's expectations of the service to be delivered and the consumer's experience resulting from the service received, as elaborated on and emphasized by Bridges (1993), who refers to this phenomenon as a "situational reference point," and Kahneman and Tversky's (1979) prospect theory. The disconfirmation paradigm theoretically supports this comparison as well. The questionnaires used in our study adopt this approach and ask participants to evaluate their specific, current postcrisis (experience) attitudes, relative to those they felt in the precrisis reference point (expectation) period (Bridges 1993; Kahneman and Tversky 1979; Zeithaml 1988).

Several studies related to service quality in the banking industry adopt the SERVQUAL instrument (Parasuraman, Berry and Zeithaml 1988; Parasuraman, Zeithaml and Berry 1985) or SERVPERF (Cronin and Taylor 1992) and consider the following dimensions: tangibles, reliability, responsiveness, assurance, and empathy (e.g., Carvalho and Leite 1999; Duncan and Elliot 2002; Paswan et al. 2004; Yavas, Bilgin, and Shemwell 1997). Other studies that focus on the specifics of financial services highlight various service attributes that clients reportedly consider when evaluating banks, including location and convenience, bank service charges, assurance, trust, the bank's reputation, friendly personnel, security, and confidentiality (Gerrard and Cunningham 2001; Kaynak and Harcar 2005). Lewis (1991) groups the various attributes of bank service quality into four dimensions: physical features and facilities, reliability, staff with customer contact, and responsiveness to clients' needs. Bahia and Nantel (2000) instead identify six dimensions: effectiveness and assurance, access, price, tangibles, services portfolio, and reliability.

Pennings, Wansink, and Meulenberg (2002) model consumer reactions to the crisis that resulted from outbreaks of mad cow disease and decompose risk into two dimensions: risk perception and risk attitude. Whereas risk perception relates to consumers' interpretation of the chance of exposure to the content of the risk, risk attitude refers to their predisposition to risk. Different dimensions may be managed with different tools. For example, the mass media can be effective in decreasing risk perceptions, but risk attitude depends on culture and can be avoided only through elimination. We therefore consider the main drivers of consumer reactions in this study.

Taylor (2006) relates varying consumers' reactions to a crisis, in the context of the reaction of the tourism industry to terrorist attacks, in terms of the impact of mass media and considers variance between media messages and reality. He finds that affected tourist destinations adopted a "dormant attrition" approach, waiting for the passage of time to diminish memories and images, or an "assertive imperative" approach by taking into account the power of the mass media and trying to redress the damage, modify consumer perceptions, and ameliorate attitudes. We extend his findings to a crisis of 
a different nature to ascertain which of these approaches emerged during the Uruguayan financial crisis.

This study specifically focuses on a relevant issue for consumers facing a financial crisis, who experience significant changes in attribute importance and attribute determinacy because of the shock of the situational context. As Anderson and Cox (1977) explain, in a stable financial environment, clients do not perceive much difference among banks with respect to a relevant attribute such as security. Generally, studies highlighting the importance of bank attributes in a stable financial context find that security is an important but not determinant attribute (Myers and Alpert 1968). But little attention considers the effect of a financial crisis on the importance and the determinance of the security and credence dimensions.

In light of these previous findings, this study investigates the crisis-propagated evolution of search, experience, and credence attributes.

\section{Data and Methodology}

\section{Data Generation}

In Stage 1 of the data generation process, we conducted six focus groups and 10 expert interviews to (a) identify pertinent variables, (b) adapt attributes cited in previous literature to the Uruguayan cultural context, and (c) assist with questionnaire design. Four focus groups took place in 2002 and two in 2003. The six focus groups were conducted in the Montevideo area, and each group contained approximately 9 participants between 25 and 67 years of age with medium to high incomes. Of these respondents, $57 \%$ were women and $43 \%$ men. The income levels were consistent with the characteristics of the Uruguayan banking industry, in which the ratio of banking clients is only 300 per 1,000 inhabitants. A professional market research institute selected the participants using proportional quota sampling to represent the key characteristics of the population. Responses were tape-recorded, transcribed, and summarized. Each interview lasted between 120 and 150 minutes. Mixed methodologies identified the most important attributes that people considered when choosing a bank and evaluating the level of service quality of a financial institution. Specifically, we used the critical incident methodology to identify the pertinent attributes and their classification. This methodology is appropriate for identifying and classifying underlying key dimensions by conducting content analyses of the stories or critical incidents as data (Gremler 2004).

During the interviews, participants were asked to remember and describe a particular event or experience in their relationship with their bank, with a focus on their evaluation of service quality and the attributes they considered relevant for their service quality evaluations and for selecting a financial institution. We recorded more than 110 incidents for further analysis that generated rich information about customers' experiences with bank service providers. Four independent researchers classified the incidents; these researchers were not familiar with service quality literature pertaining to banks but were instructed to identify the dimension of bank quality and selection in each incident. The researchers coded the incidents independently and reached an average agreement of $86 \%$. Any discrepancies were resolved by discussing key terms and jointly reviewing the critical incident codification until agreement was reached.

In addition, 10 interviews with bank experts were conducted. The interview respondents were selected from among bank managers in both public and private banks.

The content analysis of the critical incidents revealed that the construct of service quality consists of more than 20 service quality attributes that can be classified into seven broad attribute categories: trust, security, honesty, yield, good service, customer care, and other. The data generated in 2003 completed the list and introduced two additional categories of attributes: competent personnel and honesty. The 2007 interviews suggested the same list of attributes. The results of the bank expert interviews validated the categories of attributes that emerged from the focus groups and the judges' codification.

Considering findings from previous literature and the results of the qualitative study, we decided to address several specific attributes. For the credence attributes, we employed trust, which consists of bank reputation and confidence; security, which includes fulfill promise, guarantee of funds, fulfill legal requirement of public authorities, respect contracts, safety of saving accounts and deposits, and the endorsement or backing of headquarters; and honesty, which comprises banks that do not commit illegal actions against client interests, transparency, and accurate information. For the search attributes, we used yield, which indicates lower service charges, high interest payments on saving accounts, low interest rates for loans, and availability of credit with favorable terms. Finally, for the experience attributes, we utilized good service, which includes a wide range of services offered, professionalism of employees, hour's of operation, knowledgeable staff, and fast and efficient service; competent personnel, which includes a low rate of errors, promptness in correcting errors, and personnel offering good advisory services and counselling; and customer care, which comprises caring, individual attention the bank provides to its customers, reception 
received at the bank, friendliness of bank personnel, empathy, and courtesy of personnel.

Stage 2 entailed data collection through a two-wave telephone survey. We collected the first wave of data 2 weeks after the end of the "banking holiday" (2002). The follow-up survey (second wave) occurred 13 months later (2003). We also undertook a third wave of data collection in 2007. The survey questions used in this phase of the research were based on existing service quality literature and the qualitative research results. Whenever possible, the questionnaire reproduced the language and phrases used by the focus groups (questionnaires can be obtained upon request).

The questionnaires were administered to a randomly selected, stratified sample of Uruguayan bank customers in the metropolitan area of Montevideo. The sample sizes were as follows: 601 respondents for the first wave survey, 501 respondents for the second, and 609 for the third wave. These different samples helped avoid learning effects. All surveys asked the respondents to indicate the most important attributes they considered before the financial crisis and the requirements they considered most important after the crisis. This procedure reflected Zeithaml's (1988) assertion that the specific evaluation embedded in a participant's reply to questionnaires results from his or her comparison of expectations with perceptions of performance received. Similarly, it reflected the notion of a point of reference (Bridges 1993). In addition, we collected data pertaining to awareness of advertising, credibility, security, and service quality perceptions for banks operating in the Uruguayan financial market. Finally, we obtained information about the banks people patronized before and after the financial crisis.

\section{Attribute Exchange Analysis: Data and Methodology}

For the three panels (data from 2002, 2003, and 2007), we created matrices in which the rows described the most relevant attributes respondents considered in evaluating a particular bank before the financial crisis, and the columns described the most important attributes they sought from a financial entity 2 weeks after the end of the banking holiday (2002), 13 months later (2003), or 5 years later (2007). This format measured changes as asymmetric movements of flows of people between any pair of attributes. These data sets are available upon request.

Hoffman, van der Heijden, and Novak (2001) review literature about the graphical representation of square asymmetric frequency matrices that collect patterns of changes in consumers' choice behavior. Their arguments show that methodologies such as multidimensional scaling or factor analysis exhibit several limitations in displaying the skew-symmetric component (Constantine and Gower 1978). Thus, because our objective is to display asymmetry in movements between attributes provided by the financial institutions before and after the financial crisis, we use correspondence analysis (CA) of square asymmetric matrices (Greenacre 2000) and rely on XLSTAT software (Addinsoft 2007).

We focused on interpreting associations for the skewsymmetric maps. According to Constantine and Gower (1978) and Greenacre (2000), the skew-symmetric data component may be represented by points, whose relationships can be interpreted in terms of the areas of triangles formed by each pair of attributes and the origin (i.e., larger areas indicate greater deviations from symmetry). Points closer to the center of the map represent a pair of attributes with little asymmetry in the changes of a segment size due to movements of people between them. Larger changes in flows appear as attributes that are farther from the center. The direction of positive flows depends on the relative orientation of the points; for our study, we interpret flow in a counterclockwise direction.

To assess the significance of the skew-symmetric component, we employed the McNemar-Bowker test (Agresti 1990), using R software (R Development Core Team 2007). After we verified the significance of the skew-symmetric component of each analysis, we compared the magnitude of the skew-symmetric components among the three analyses that corresponded to the three periods. To compare different panels with the same number of rows and columns, we determined their variances by noting their respective total inertias, defined as the sum of the squared standardized residuals of relative frequencies (Greenacre 2006). In this case, we should not compare the total inertia of the three panels but rather the total inertia corresponding to the skew-symmetric component.

\section{Segmentation Analysis: Data and Methodology}

We require a methodology that can describe the association between types of banks and the attributes consumers consider before and after the crisis for each of the periods analyzed. We possess two different sets of categorical variables - type of bank and attributes-which supports our use of CA (e.g., Greenacre 2007). We might apply a simple CA for each period, but as the number of levels for each variable increases, it becomes complicated to associate the sources of communality and differences between the two analyses; moreover, the analyses are comparable, but only at some points. However, an extension of simple CA (Greenacre 2004), the CA of matched 
matrices, can display a communality map that contains the type of bank-attribute combinations required by customers that are not context dependent, that is, with strong associations in both contexts. A difference map in turn shows the type of bank-most important attribute combinations that display stronger associations in one stage or another (i.e., before or after the crisis) but not simultaneously.

We interpret the difference map as follows: Closeness between a financial institution and an attribute indicates that customers of this financial entity value this attribute more after the financial shock occurs but not before. Distant locations with respect to both axes indicate that the attribute was the most important when evaluating that particular financial institution before the crisis but not after. We verify the accuracy of this map according to the proportion of the difference inertia captured by the first two principal axes of difference. For additional geometrical details, please see Greenacre (2004).

\section{Analysis}

\section{First-Period Analysis}

The skew-symmetric component displays the asymmetric flows related to preferences for attributes before and after the financial crisis. The first two dimensions related to the skew-symmetric component are the fourth and fifth principal axes, which represent $99.9 \%$ of the total variance of the skew-symmetric component. The McNemar-Bowker test value suggests rejecting the null hypothesis of no asymmetry between preferences before and after the crisis (McNemar's chi-square $=78.3, d f=$ $15, p$ value $<.0001)$.

As we reveal in Figure 1a, the largest triangle corresponds to the points for yield and security and the center of the map, followed by that formed by yield, trust, and the center of the map. The largest difference emerges from respondents who considered yield the most important attribute before the crisis but sought security afterward. The same explanation holds for trust. That is, trust and security attributes are located on the same line through the origin. Because there is no area between them, no asymmetric in-flow occurs.

In a crisis situation, trust and security appear as determinant attributes for differentiating bank products, whereas yield is no longer such an attribute; the qualitative analysis reveals however that most banks reacted to the crisis by increasing their offered yield through higher interest rates. The sources of return, net of risk premium, come from trust and security. This result corroborates the numerical results. In the 2002 and 2003 surveys, respondents evaluated the security level of eight commercial
Figure 1a

\section{Correspondence Analysis of Skew-Symmetric Component T: Data 2002}

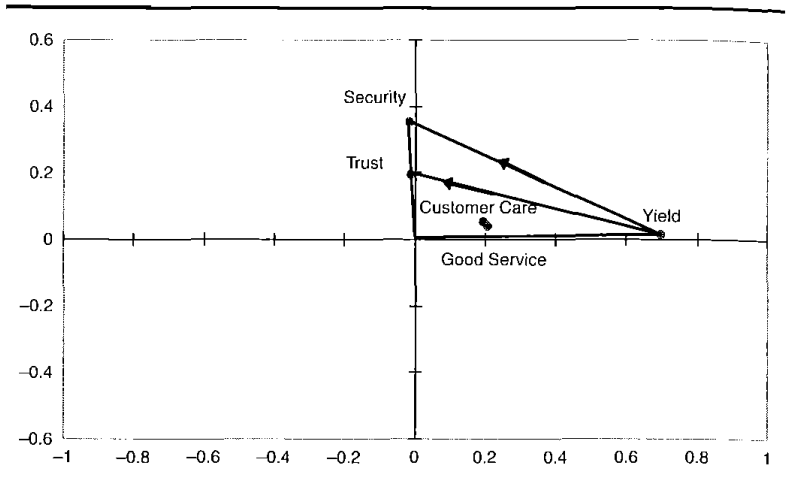

Note: Fourth and fifth principal axes represent $99.9 \%$ of the total variance of the skew-symmetric component.

banks operating in Uruguay on a scale of 1 to 5 . The mean for security ranged from 1 to 5 , and the overall mean scores were 3.11 and 3.29 , with standard deviations of 0.80 and 0.89 , for the first and second surveys, respectively. The dispersions in the evaluations in both surveys demonstrate that in a financial crisis situation, security is not only an important attribute but also a differentiating one.

To detect heterogeneous patterns in consumers' reactions, we added information related to the type of bank of which each respondent is a client, distinguishing among publicly owned banks (BP), privately owned national banks $(\mathrm{BN})$, private international banks $(\mathrm{BI})$, and savings and loans cooperatives (BC). In Figure 2a, we show the map derived from applying the $\mathrm{CA}$ of matched matrices.

The first principal axis provides the main source of variance for the difference component. We also included the second most important dimension for differences (fifth principal axis), on which cooperative banks are better represented. Together, these dimensions account for $95.4 \%$ of the total variance of differences. Because CA uses singular value decomposition, the resulting eigenvalues appear in a decreasing order (Greenacre 2007). In our analysis, the first (highest) eigenvalue corresponds to the differences component, indicating that it is relevant for this analysis.

Because we investigated differences in attribute-bank associations between two different scenarios, we can distinguish positive differences due to positive scalar products formed by attributes and banks, which suggests a stronger association after the financial crisis (Greenacre 2004). The negative scalar products, in contrast, indicate that the association was stronger before the shock. From 
Figure 2a

Correspondence Analysis of Matched Matrices: Difference Component-Data 2002

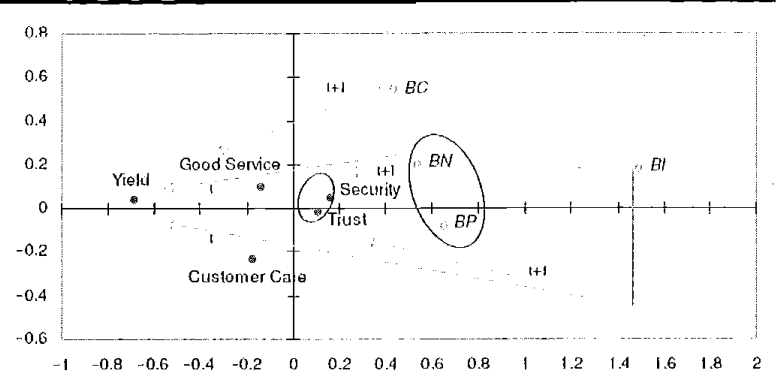

Note: First and fifth principal axes represent $95.4 \%$ of the total variance of differences. $\mathrm{BP}=$ public bank, $\mathrm{BN}=$ national or domestic bank, $\mathrm{BI}=$ international bank, $\mathrm{BC}=$ cooperative banks.

Figure $2 \mathrm{a}$, we recognize that higher positive differences exist for the trust and security attributes among clients of international banks, which indicates that these consumers consider trust and security more important after the shock. The highest negative value for these banks corresponds to the yield attribute, thus emphasizing that clients attributed higher value to this attribute before the crisis. We further note that a cluster composed of domestic and public banks follows the same pattern but with smaller differences. Finally, the clients of cooperative banks regarded the good service attribute as more important after, but not before, the financial crisis.

\section{Second-Period Analysis}

Repeating the analysis for the 2003 data demonstrates the stability of the results. The skew-symmetric analysis in Figure $1 b$ reveals some strong similarities to Figure 1a. The fourth and fifth principal axes represent the two principal axes of the skew-symmetric component and account for $99.2 \%$ of the variance.

Again, asymmetry in flows becomes evident in the movements from yield to being honest and security and trust. The McNemar-Bowker test value also enables us to reject the null hypothesis of no asymmetry between preferences before and after the crisis (McNemar's chi-square $=131.6207, d f=15, p$ value $<2.2 \mathrm{e}-16$ ).

This stable result, with higher values for trust and security compared with yields, even a year after the financial crisis, may emerge because, as we mentioned previously, Uruguayan banks reacted very quickly to the financial crisis by increasing interest rates (yield). Because all banks reacted in a similar way, yield cannot be a determinant attribute, whereas trust and security can. Furthermore, qualitative studies reveal that the
Figure 1b

\section{Correspondence Analysis of Skew-Symmetric} Component T: Data 2003

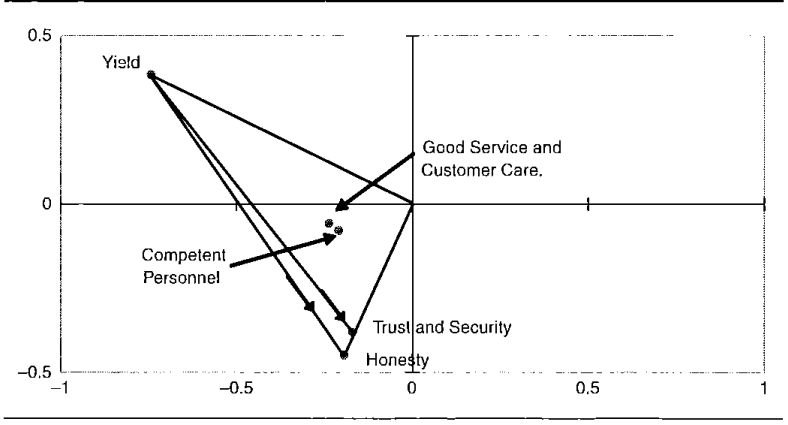

Note: Fourth and fifth principal axes represent $99.2 \%$ of the total variance of the skew-symmetric component.

communication strategies implemented were not very effective, because customers were not certain if they had emerged from the crisis cycle. Rates of spontaneous awareness of banks' advertising activities were quite poor, ranging from $2 \%$ to $16 \%$. In such a situation, especially when clients are highly risk averse (Hofstede 1991), it makes sense that the results remain stable after just 1 year. The different types of bank organization also might help explain these results.

Figure $2 \mathrm{~b}$ displays the first and third principal axes, which account for $98.45 \%$ of the total inertia of differences. We again note that the first dimension, which captures the highest eigenvalue, belongs to the difference analysis. As in our previous analysis, the first dimension of differences is determined mainly by the attributes representing yield, trust, and security, plus honesty.

From Figure $2 b$, we recognize some differences between clients of the different banks, but the patterns remains quite similar to those described for 2002 . The similarity in responses among customers of both public and international banks reveals that a year after the crisis, public banks' clients exhibited essentially the same perceptions about risk premiums as those of international banks did. However, clients of national banks considered trust and security more important. National banks were the most vulnerable to the crisis, and financial authorities had to liquidate some of them. Thus, the result highlights the greater standard deviation related to security perceptions between banks.

\section{Third-Period Analysis}

The arguments provided by Pennings, Wansink, and Meulenberg (2002) do not match our results, because in our study, even after the risk had been eliminated, 
Figure 2b

Correspondence Analysis of Matched Matrices: Difference Component-Data 2003

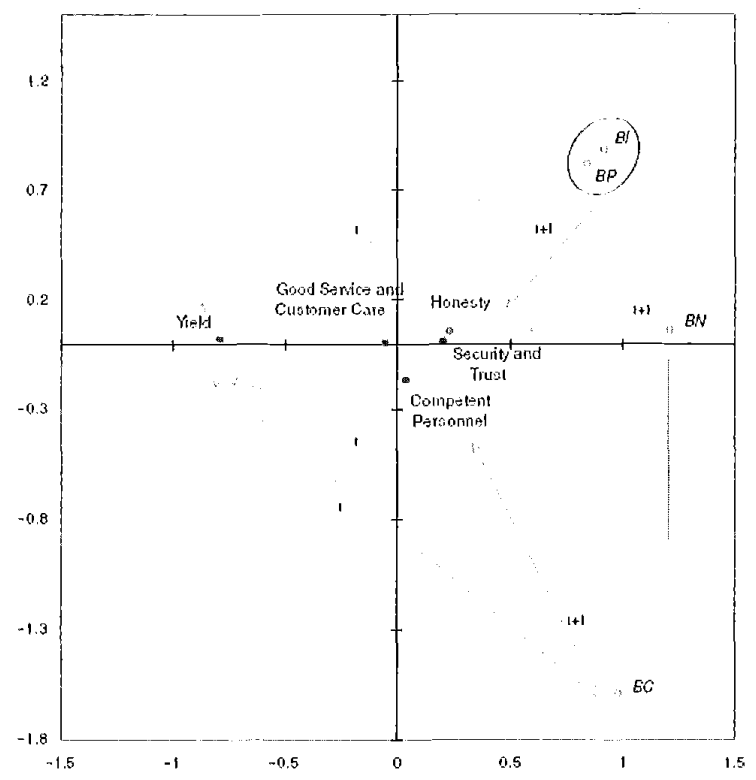

Note: First and third principal axes represent $98.45 \%$ of the total inertia of differences. $\mathrm{BP}=$ public bank, $\mathrm{BN}=$ national or domestic bank, $\mathrm{BI}=\mathrm{I}$ nternational bank, $\mathrm{BC}=$ cooperative banks.

customers did not change their attitudes because they were unsure if they had left the crisis cycle. If communication was not effective, the assertive imperative approach apparently did not work in this scenario, which provides some justification for the dormant attrition approach (Taylor 2006). We repeated the analysis 5 years later to determine if time indeed represents a necessary factor to create changes in customers' reactions to a financial crisis in a country characterized by high levels of uncertainty avoidance (Hofstede 1991).

The skew-symmetric map for 2007 displays the same shape as the previous maps, as we show in Figure 1c.

However, the difference from the previous analyses is that the amount of inertia captured is much smaller. The McNemar-Bowker test value still enables us to reject the null hypothesis of no asymmetry between preferences before and after the crisis though (McNemar's chisquare $=62.5779, d f=15, p$ value $=9.042 \mathrm{e}-08$ ).

Next, we compare the variances from panels with the same number of rows and columns by comparing the values of their respective total inertias (Greenacre 2006), as we show in Table 1.

The principal axes corresponding to the skew-symmetric analysis are the fourth and fifth axes for 2002 and
Figure 1c

\section{Correspondence Analysis of Skew-Symmetric} Component T: Data 2007

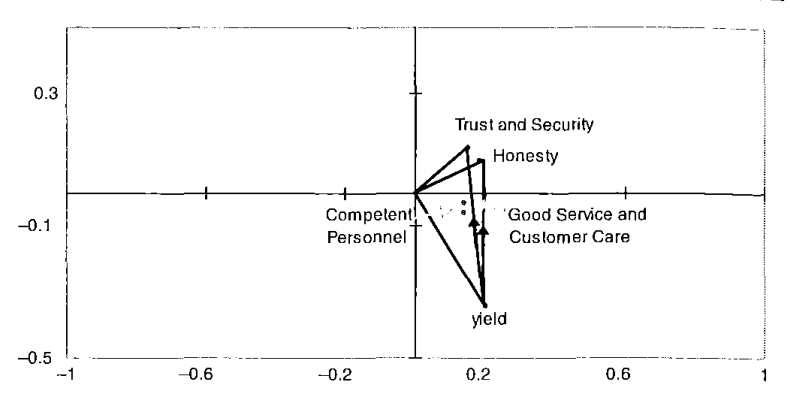

Note: Fifth and sixth principal axes represent $96.4 \%$ of the total variance of skew-symmetric component.

2003 but the fifth and sixth axes for 2007. The inertia values reveal that the skew-symmetric analysis was more important in 2003, 1 year after the crisis. By 2007, feelings of insecurity had started to abate, in line with the dormant attrition approach.

\section{Conclusions, Limitations, and Further Research}

We analyze the effect of a severe financial crisis on changes in the relative importance of the main attributes people seek from their financial institutions. Specifically, before the financial crisis, we find that most clients were focused on obtaining a high yield (search attribute), whereas after the crisis began, they started to prefer security and trust (credence attributes). This phenomenon highlights another asymmetry, of lesser importance, between service and customer care on one hand versus security and trust on the other hand. This secondary segment of consumers placed a premium on banks offering good service and close customer relationships before the crisis but then emphasized security and trust afterward. This finding might result from the decreased width of the zone of tolerance for security and trust because of increases in the level of adequate expectations (Parasuraman, Berry, and Zeithaml 1991).

We also examine whether these changes in attitudes, in terms of the relative importance of the attributes of a financial entity, are short-lived and transitory or persist over time. Taking into account efforts such as public advertising campaigns and the resolution of the problem, we find that changes in attitude are not just stable, and the skew-symmetric component takes on greater weight in the second analysis (i.e., higher percentages of total 
Table 1

Inertia Components

\begin{tabular}{|c|c|c|c|c|c|c|c|c|c|}
\hline & Fl & F2 & F3 & $\mathrm{F} 4$ & F5 & F6 & F7 & F8 & F9 \\
\hline \multicolumn{10}{|l|}{2002} \\
\hline Eigenvalue & 0.451 & 0.333 & 0.286 & 0.053 & 0.053 & 0.040 & 0.000 & 0.000 & 0.000 \\
\hline$\%$ Variance & 37.079 & 27.334 & 23.486 & 4.370 & 4.370 & 3.324 & 0.019 & 0.019 & 0.000 \\
\hline$\%$ Accumulated & 37.079 & 64.421 & 87.898 & 92.268 & 96.637 & 99.961 & 99.981 & 100 & 100 \\
\hline \multicolumn{10}{|l|}{2003} \\
\hline Eigenvalue & 0.396 & 0.345 & 0.256 & 0.117 & 0.117 & 0.001 & 0.001 & 0.001 & 0.000 \\
\hline$\%$ Variance & 32.121 & 27.952 & 20.706 & 9.492 & 9.474 & 0.093 & 0.067 & 0.075 & 0.000 \\
\hline$\%$ Accumulated & 32.121 & 60.073 & 80.779 & 90.271 & 99.745 & 99.838 & 99.925 & 100 & 100 \\
\hline \multicolumn{10}{|l|}{2007} \\
\hline Eigenvalue & 0.548 & 0.425 & 0.354 & 0.173 & 0.027 & 0.027 & 0.001 & 0.001 & 0.000 \\
\hline$\%$ Variance & 35.241 & 27.324 & 22.776 & 11.099 & 1.734 & 1.734 & 0.046 & 0.046 & 0.000 \\
\hline$\%$ Accumulated & 35.241 & 62.565 & 85.341 & 96.440 & 98.174 & 99.908 & 99.954 & 100 & 100 \\
\hline
\end{tabular}

variance). No further comparison of these analyses is possible because we rely on and draw the data from different samples. However, we identify an important flow of people who before the crisis perceived yield as the most important attribute but after the crisis attached comparatively more importance to the attributes of security and trust and honesty. A year after the bank crisis, the public continued to place a premium on these attributes.

In a normal financial environment, customers tend to take security for granted and assume that all banks provide nearly the same level. That is, security is an important but not determinant attribute (Anderson and Cox 1977). Yet in the first and second samples, security became an important attribute that competing banks possessed to different degrees and thus a determinant attribute. Yield, in contrast, became less of a determinant factor, because banks used it homogeneously in their strategic reactions to the crisis.

Uruguayan banks perceived the critical importance of security and launched institutional advertising campaigns emphasizing security, stability, endorsement, seriousness, and ethics in their attempts to recover public confidence. Yet this study reveals no clear evidence of the effectiveness of these marketing tactics; instead, though the security scores show slight signs of improvement in 2003 for almost all banks, the advertising campaigns have insignificant impacts on awareness. Specifically, $29 \%$ of the respondents could not remember any advertisements, and 50\% of them stated that none of the advertisements succeeded in transmitting a message of tranquility. The contribution of advertising campaigns to the incipient recuperation of confidence in banking institutions in the second wave of research is inconclusive. These results align with evidence documented by Ford, Smith, and Swasy (1990) regarding the high degree of skepticism surrounding credence ad claims.

According to Pennings, Wansink, and Meulenberg (2002), marketers must take consumers' risk attitudes into account when reacting to a crisis. If consumer behavior during a crisis situation is driven primarily by risk attitudes, such as extreme risk aversion, as in the case of Uruguay, and if the risk is systemic, not productspecific, the only effective remedy may lie in eliminating the risk and conveying that elimination through an authoritative figure associated with positive memories. Communication efforts alone will not be effective. The type, source, and association of communication may be more important than the communication itself.

Furthermore, advertising campaigns are not the best way to communicate credence attributes (Ford, Smith, and Swasy 1990; Wright and Lynch 1995). To change perceptions about credence attributes, institutions must develop an integrative communication strategy. During crisis situations involving service institutions, customers suffer anxiety and greater uncertainty, which enhances their need for information and makes them more receptive to word-of-mouth information. Therefore, influencing word-of-mouth communications positively would seem to be a key priority for service managers.

Personnel in contact with clients may offer a source of more reliable information than advertising, especially with regard to credence attributes for which the consumption experience engenders more trustworthy information than advertising (Wright and Lynch 1995). Obviously, this communication strategy should be 
accompanied by measures designed to restore trust and security and eliminate the sources of risk. An out-ofmodel conjecture also points to the probable importance of financial authorities in mitigating financial crises. Silber's (2007) recent findings show that the 1933 run on American banks was resolved when President Franklin Roosevelt restored trust and confidence in the financial system by passing the Emergency Banking Act, which introduced a de facto deposit insurance and eliminated public perceptions of a high-risk environment. This aspect of communication may relate closely to the retrieval strategy raised by Tybout, Calder, and Sternthal (1981) regarding the notion of implausible rumors: The judicious choice of an appropriate stimulus can prompt the retrieval of thoughts that move people away from rumor-stimulated associations.

In 2007, 5 years after the crisis, the feeling of insecurity apparently had dissipated, as the increase in the flows of customers who favored yield attributes reveals. Even in a country characterized by a high level of risk aversion, the effective management of the crisis by financial authorities, coupled with the passage of time, decreased the significance of trust and security as determinant attributes. That is, our research shows that credence attributes such as security and trust gain importance, relative to search attributes such as yield, in the medium term but not in the much longer term-as long as the fundamental determinants of behavior are restored to their precrisis levels.

Another interesting phenomenon that emerges from this research relates to different consumer reactions to crisis depending on the type of financial institution. International, national, and domestic banks appear to experience the same source of differentiation before and immediately after the crisis, based on the yield net of risk premium. However, a difference pertains to how to accomplish this net, that is, through higher yield or lower risk. The greater difference for international banks compared with national ones may reflect that the clients of international banks tend to belong to a more risk-averse segment that hopes to gain security through the endorsement of international parent banks. After a crisis though, our results suggest that savings and loans cooperatives can improve their competitive advantages by focusing more on services.

A year after the crisis, clients of both international and public banks showed homogeneous perceptions of risk premium, and clients of national banks considered trust and security more important. National banks were the most vulnerable to the crisis, and some even suffered liquidation by financial authorities. Their clients therefore apparently needed more time to recapture the previous perception of security and trust. Furthermore, we again find a distinction marking clients of savings and loan cooperatives; mainly, unlike clients of private and public banks, they place greater value on competent personnel.

As its major contribution, this study uncovers major attributes, their dynamic evolution resulting from a major systemic (financial) crisis, and the differential effect of different (banking) organizations. This study therefore represents a first step in a continuing investigation, in which we intend to employ inferential methodologies to establish causal relations among the crisis, the attributes, and the various organizational forms of the banks involved. Such an analysis will enable us to measure the efficiency of the various communication channels and forms used by the different banking organizations and hence assess their managerial effectiveness. In addition, in further research, we hope to compare the results of this work with results related to other financial crises, such as the recent subprime mortgage crisis in the United States, to test whether different scores of the uncertainty avoidance cultural index imply different time requirements for the recovery to a precrisis situation.

Finally, credence attributes are of particular relevance in business environments plagued by problems concerning contract enforcement, high levels of uncertainty, and limited trustworthiness-features that are crucial for banking and other service industries. The high level of intangibility of financial services determines the relevance of credence attributes and accentuates the potency of word-of-mouth communications. Because these characteristics are common to a large range of service industries, the results presented herein, which pertain to the banking sector, also may generalize to other service industries that experience similar industry-wide exposure and vulnerability to crises.

\section{References}

Addinsoft (2007), XLSTAT-Statistical Software for MS Excel. http://www.xlstat.com/.

Agresti, Alan (1990), Categorical Data Analysis. New York: John Wiley.

Anderson, W. Thomas, and Eli P. Cox (1977), "Determinance Versus Importance in Bank Selection Criteria," Jounal of Marketing, 40 (January), 85-87.

Bahia, Kamilia, and Jacques Nantel (2000), "A Reliable and Valid Measurement Scale for the Perceived Service Quality of Banks," International Joumal of Bank Marketing, 18 (2), 84-91.

Belk, W. Russell (1974), "An Exploratory Assessment of Situational Effects in Buyer Behavior," Journal of Marketing Research, 11 (May), 156-163.

Blois, Kieth (1999), "Trust in Business to Business Relationships: An Evaluation of Its Status," Jounal of Management Studies, 36 (2), 197-215. 
Boot, Arnoud (2000), "Relationship Banking: What Do We Know?," Journal of Financial Intermediation, 9 (1), 7-25.

Boschi, Melisso (2005), "International Financial Contagion: Evidence from the Argentine Crisis of 2001-2002," Applied Financial Economics, 15 (3), 153-164.

Bridges, Eileen (1993), "Service Attributes: Expectations and Judgments," Psychology \& Marketing, 10 (3), 185-197.

Caprio, Gerald, and Daniela Klingebiel (1996), "Bank Insolvencies: Cross-Country Experience," working paper, World Bank Policy and Research, Washington, DC.

Carvalho, A. Frederico, and Valdeci F. Leite (1999), "Attribute Importance in Service Quality: An Empirical Test of PBZ Conjecture in Brazil," International Joumal of Service Industry Management, 10 (5), 487-504.

Constantine, A. G., and John C. Gower (1978), "Graphical Representation of Asymmetric Matrices," Applied Statistics, 27 (3), 297-304.

Cronin, J. Joseph, and Steven A. Taylor (1992), "Measuring Service Quality: A Re-examination and Extension," Journal of Marketing, 56 (July), 55-68.

Duncan, Elisabeth, and Greg Elliot (2002), "Customer Service Quality and Financial Performance among Australian Retail Financial Institutions," Journal of Financial Services Marketing, 7 (1), 25-41.

Ford, Gary, Darlene B. Smith, and John L. Swasy (1990), "Consumer Skepticism of Advertising Claims: Testing Hypotheses from Economics of Information," Journal of Consumer Research, 16 (4), 433-441.

Gerrard, Philip, and J. Barton Cunningham (2001), "Bank Service Quality: A Comparison between a Publicly Quoted Bank and Govermment Bank in Singapore," Joumal of Financial Services Marketing, 6 (1), 50-66.

Greenacre, Michael J. (2007), Correspondence Analysis in Practices. Boca Raton, FL: Chapman \& Hall/CRC.

- (2006), "Tying Up the Loose Ends in Simple Correspondence Analysis," in COMPSTAT 2006-Proceedings in Computational Statistics, Vol. 35, A. Rizzi and M. Vichi, eds. Heidelberg, German: Physica Verlag, 163-186.

_ (2004), "Analysis of Matched Matrices," Joumal of Applied Statistics, 30 (10), 1101-1113.

- (2000), "Correspondence Analysis of Square Asymmetric Matrices," Applied Statistics, 49 (3), 297-310

Gremler, Dwayne (2004), "The Critical Incident Technique in Service Research," Joumal of Service Research, 7 (1), 65-89.

Hennig-Thurau, Thorsten, Kevin P. Gwinner, and Dwayne Gremler (2002), "Understanding Relationship Marketing Outcomes: An Integration of Relational Benefits and Relationship Quality," Jounal of Service Research, 4 (3), 230-248.

Hoffman, Donna L., Peter G. M. van der Heijden, and Thomas P. Novak (2001), "Mapping Asymmetry in Categorical Consumer Choice Data," working paper, Sloan Centre for Internet Retailing, University of California.

Hofstede, Geert (1991), Cultures and Organizations. London: Paston Press.

Hoggarth, Glenn, Ricardo Reis, and Victoria Saporta (2002), "Costs of Banking System Instability: Some Empirical Evidence," Journal of Banking \& Finance, 26 (5), 825-855.

Kahneman, Daniel, and Amos Tversky (1979), "Prospect Theory: An Analysis of Decision Under Risk," Econometrica, 47 (2), 263-291.
Kaynak, Erdener, and Tallha D. Harcar (2005), "American Consumers' Attitudes Towards Commercial Banks: A Comparison of Local and National Bank Customers by Use of Geodemographic Segmentation," International Joumal of Bank Marketing, 23 (1), 73-89.

Lewis, Barbara R. (1991), "Service Quality: An International Comparison of Bank Customers' Expectations and Perceptions," Jounal of Marketing Management, 7 (1), 47-62.

Miller, E. Kenneth, and James L. Ginter (1979), "An Investigation of Situational Variation in Brand Choice Behavior and Attitude," Journal of Marketing Research, 16 (February), 111-123.

Myers, James H., and Mark I. Alpert (1968), "Determinant Buying Attitudes: Meaning and Measurement," Journal of Marketing, 32 (4), 13-20.

Nelson, Phillip (1974), "Advertising as Information," Joumnal of Political Economy, 82 (4), 729-754.

(1970), "Information and Consumer Behavior," Joumal of Political Economy, 78 (2), 311-329.

Parasuraman, A., Valerie A. Zeithaml, and Leonard L. Berry (1985), "A Conceptual Model of Service Quality and its Implications for Future Research," Journal of Marketing, 49 (Fall), 41-50.

Parasuraman, A., Leonard L. Berry, and Valerie A. Zeithaml (1991), "Understanding Customer Expectations of Service," Sloan Management Review, 32 (3), 39-48.

(1988), "SERVQUAL: A Multiple-Item Scale for Measuring Consumer Perceptions of Service Quality," Joumal of Retailing, 64 (Spring), 12-40

Paswan, Audhesh K., Nancy Spears, Ron Hasty, and Gopala Ganesh (2004), "Search Quality in the Financial Services Industry: A Contingency Perspective," Jounal of Services Marketing, 18 (5), 324-338.

Pennings, Joost M. E., Brian Wansink, and Matthew, T. G. Meulenberg (2002), "A Note on Modeling Consumer Reactions to a Crisis: The Case of the Mad Cow Disease," International Journal of Research in Marketing, 19 (1), 91-100.

R Development Core Team (2007), R: A Language and Environment for Statistical Computing. $\mathrm{R}$ Foundation for Statistical Computing, Vienna, Austria. http://www.R-project.org/.

Samartín, Margarita (2002), "Suspension of Convertibility Versus Deposit Insurance: A Welfare Comparison," European Finance Review, 6 (2), 223-224.

Silber, William. L. (2007), "Why Did FDR's Bank Holiday Succeed?," working paper, New York University.

Smith, Denis (2005), "Business (Not) as Usual: Crisis Management, Service Recovery and the Vulnerability of Organizations," Joumal of Services Marketing, 19 (5), 309-320.

Srinivasan, Srini, and Brian D. Till (2002), "Evaluation of Search, Experience and Credence Attributes: Role of Brand Name and Product Trial," Jounal of Product and Brand Management, 11 (7), 417-432.

Taylor, Peter A. (2006), "Getting Them to Forgive and Forget: Cognitive Based Marketing Responses to Terrorist Acts," International Journal of Tourism Research, 8 (3), 171-183.

Teas, R. Kenneth, and Thomas E. De Carlo (2004), "An Examination and Extension Zone-of-Tolerance Model. A Comparison to Performance-Based Models of Perceived Quality," Journal of Service Research, 6 (3), 272-286.

Tybout, Alice M., Bobby J. Calder, and Brian Sternthal (1981), "Using Information Processing Theory to Design Marketing Strategies," Journal of Marketing Research, 18 (1), 73-79. 
Wright, Alice, and John G. Lynch, Jr. (1995), “Communication Effects of Advertising Versus Direct Experience When Both Search and Experience Attributes are Present," Journal of Consumer Research, 21 (4), 708-718.

Yavas, Ugur, Zeynep Bilgin, and Donald J. Shemwell (1997), "Service Quality in the Banking Sector in an Emerging Economy: A Consumer Survey," International Joumal of Bank Marketing, 15 (6), 217-223.

Zeithaml, Valerie A. (1988), "Consumer Perceptions of Price, Quality and Value: A Means-End Model and Synthesis of Evidence," Journal of Marketing, 52 (3), 2-22.

Zurawicki, Leon, and Nestor Braidot (2005), "Consumers During Crisis: Responses from the Middle Class in Argentina," Journal of Business Research, 58 (8), 1100-1109.

Moshe Kim is a professor of economics at University of Haifa, Israel and currently at Universitat Pompeu Fabra, Barcelona Spain. $\mathrm{He}$ is founder and codirector of the Barcelona Banking Summer School (BBSS) at the Barcelona Graduate School. His research interests include firm-bank relationships, imperfect banking competition, and financial systems. Kim has recently published a book titled Microeconometrics of Banking, Oxford University Press. His papers have been published in journals such as the Journal of Finance, Journal of Financial Intermediation, Jounal of Monetary Economics, International Economic Review, Journal of Banking and Finance, Jounal of Money Credit and Banking, International Journal of Industrial Organization, and Journal of Business, and Economics Statistics.

Nora Lado is a marketing researcher at Carlos III University of Madrid. Lado's research concerns several categories: the measurement of the market orientation degree of the service firms and its consequences, the study of international marketing strategies and brand equity issues. Lado has published in Joumal of Business Research, European Journal of Marketing, International Marketing Review, and Intemational Joumal of Service Industry Management, among others.

Anna Torres is a marketing researcher at Universitat Pompeu Fabra. Her research is focused in several categories: branding, international marketing, and ethics in marketing. Torres has published in journals like International Journal of Research in Marketing, European Journal of Operational Research, and Food Quality and Preference. 